\title{
State Driver Stress as a Function of Occupational Stress, Traffic Congestion, and Trait Stress Susceptibility
}

\author{
Wickens, C. M., \& Wiesenthal, D. L.
}

Version Post-Print/Accepted Manuscript

$\begin{aligned} \text { Citation } & \text { Wickens, C. M., \& Wiesenthal, D. L. (2005). State driver stress as a } \\ \text { (published version) } & \text { function of occupational stress, traffic congestion, and trait stress } \\ & \text { susceptibility. Journal of Applied Biobehavioral Research, 10, 83-97. }\end{aligned}$

Publisher's Statement This is the peer reviewed version of the following article: Wickens, C. M., \& Wiesenthal, D. L. (2005). State driver stress as a function of occupational stress, traffic congestion, and trait stress susceptibility. Journal of Applied Biobehavioral Research, 10, 83-97, which has been published in final form at https://dx.doi.org/10.1111/j.17519861.2005.tb00005.x. This article may be used for non-commercial purposes in accordance with Wiley Terms and Conditions for SelfArchiving.

\section{How to cite TSpace items}

Always cite the published version, so the author(s) will receive recognition through services that track citation counts, e.g. Scopus. If you need to cite the page number of the TSpace version (original manuscript or accepted manuscript) because you cannot access the published version, then cite the TSpace version in addition to the published version using the permanent URI (handle) found on the record page. 
Running head: Predicting State Driver Stress

\author{
State Driver Stress as a Function of \\ Occupational Stress, Traffic Congestion, and Trait Stress Susceptibility
}

Christine M. Wickens and David L. Wiesenthal

York University

Toronto, Ontario, Canada 


\begin{abstract}
Drivers identified as having either high or low trait stress were interviewed over cellular telephones when experiencing either high or low traffic congestion to assess state driver stress. State stress was greater when experiencing high traffic congestion. In both conditions, time urgency and perceiving driving to be stressful were predictors of state driver stress. Perceived control was a significant negative predictor of state driver stress in high traffic congestion, and it approached significance as a negative predictor of state stress in the low congestion condition. Occupational stress only predicted state driver stress in low traffic. An interaction between trait driver stress and occupational stress approached significance in the low congestion condition. No gender differences in state driver stress were found.
\end{abstract}


State Driver Stress as a Function of

Occupational Stress, Traffic Congestion, and Trait Stress Susceptibility

According to the transactional model of driver stress, negative cognitive appraisals of the driving situation are responsible for producing driver stress (Gulian, Matthews, Glendon, Davies, \& Debney, 1989; Matthews, 2001; Matthews, Dorn, \& Glendon, 1991). Drivers' interpretations of roadway situations, as well as resulting stress levels, are influenced by factors both related and unrelated to the driving environment. Traffic congestion often serves as the environmental stressor that is primarily responsible for driver stress. Similarly, in terms of individual differences, some motorists have a greater propensity toward driver stress. These high trait stress drivers are more likely to report stress reactions within actual driving conditions (Hennessy \& Wiesenthal, 1997,1999; Wiesenthal, Hennessy, \& Totten, 2000). Hennessy, Wiesenthal, and Kohn (2000) examined the role of daily hassles in the experience of state driver stress and found that in conditions of high traffic congestion, state driver stress was predicted by the interaction of daily hassles and trait driver stress. Specifically, nondriving demands (i.e., hassles) were carried forward to the driving environment and had a negative impact on state driver stress levels, although only among high trait stress drivers.

A wide range of life events and daily pressures can accumulate and result in the experience of stress (Kohn, Hay, \& Legere, 1994). Moreover, it does not matter whether an individual is aware of these situations. If he or she deals with them ineffectively, these pressures can make the experience of subsequent hassles even more stressful (Kohn \& Macdonald, 1992). Perhaps the single most significant contribution to each individual's accumulation of stress is the workplace. In terms of both time and importance, employment occupies a primary part of life, as 
well as constituting a major source of stress (Cooper \& Payne, 1988). As with daily hassles, the common daily pressure of occupational stress may contribute to built-up tension that can suddenly be released in the driving environment by a seemingly minor traffic altercation (Gulian et al., 1989). Consistent with the transactional model of driver stress (Gulian et al., 1989; Matthews, 2001; Matthews et al., 1991), the experience of job stress may also encourage negative cognitive appraisals of specific road incidents and of driving in general, increasing state driver stress and, possibly, aggressive driving. Alternately, occupational stress may interfere with the motorist's ability to attend to the driving environment.

The current study was designed to replicate and extend previous findings concerning the interactions between situation and person factors when determining state driver stress levels. In terms of replication, the current study assessed the role of traffic congestion and trait driver stress in determining state driver stress levels. Extending the findings concerning the effect of daily hassles on state driver stress, the current study also examined the impact of occupational stressors. Based on the findings of previous research and the transactional model of driver stress (Gulian et al., 1989; Matthews, 2001; Matthews et al., 1991), four hypotheses were posited:

1. State driver stress would be greater in high than in low traffic congestion.

2. Time urgency would lead to greater state driver stress.

3. In low traffic congestion, state driver stress would be greater among high trait stress drivers.

4. In high traffic congestion only, state driver stress would be predicted by the interaction of occupational stress and trait driver stress susceptibility. Specifically, state driver stress would be greater among high trait stress drivers, but it would be exaggerated among those with elevated occupational stress. 


\section{Method}

\section{Participants}

A snowball sample of respondents obtained through personal contact and word of mouth was originally sought within one office of the Toronto, Ontario, municipal government. This method of selection would have minimized variability that could be attributed to alternate job types, work schedules, and work environments. In order to be included in the sample, the majority of the participant's commute from work to home, including the two periods of assessment of the dependent variable, had to be made along a major arterial motorway in the absence of passengers. In return for their participation, respondents were entered into a lottery for a $\$ 100$ prize.

The final sample included 42 participants: 29 males and 13 females. In addition, six other participants were eliminated from analysis because they failed the manipulation check that confirmed the perception of two differing levels of traffic congestion. Five additional participants were eliminated for violating the main criteria for participation (i.e., driving with a passenger in the vehicle, assessment of the dependent variable on city streets rather than on a major highway, or driving to another place of work instead of driving home). Despite efforts to obtain a homogeneous sample of full-time employees drawn from the same municipal government department, difficulty with participant recruitment led to the solicitation of full-time employees from a wide variety of both private and public corporations in Toronto. Participants ranged in age from 20 to 60 years, with an average age of 36.3 years $(S D=9.2)$. Their mean commuting trip lasted an astonishing 2.6 hours $(S D=1.6)$ each day. 


\section{Measures}

Driving Behavior Inventory - General (DBI-Gen; Gulian et al., 1989). Trait driver stress was measured using the DBI-Gen. The current study used a version of this measure consisting of 11 items that are intended to evaluate a general disposition, or trait susceptibility, to driver stress. Previous research has established the DBI-Gen as a valid, robust, and reliable measure of trait driver stress (Glendon et al., 1993; Hennessy \& Wiesenthal, 1997), and Matthews et al. (1991) found the DBI-Gen to have high validity in predicting predispositions to driver stress. The 11item version of the scale also attained high reliability $(\alpha=.80$ to .90 ; Hennessy $\&$ Wiesenthal, 1997; Hennessy et al., 2000).

State Driver Stress Questionnaire (SDSQ; Hennessy \& Wiesenthal, 1997). The SDSQ is intended to assess the state experience of driver stress; thus, it has been designed to be administered verbally in actual driving situations. It is comprised of 11 items similar to those from the DBI-Gen, as well as 10 items from the Stress Arousal Checklist (Mackay, Cox, Burrows, \& Lazzerini, 1978). The SDSQ demonstrated high reliability in low ( $\alpha=.92$ to .94$)$ and high ( $\alpha=.90$ to .97$)$ traffic congestion conditions (Hennessy \& Wiesenthal, 1997, 1999; Hennessy et al., 2000; Wiesenthal et al., 2000). Five additional items were added to serve as manipulation checks and to assess time urgency and perceptions of control.

Job Stress Survey (JSS; Spielberger \& Vagg, 1999). The JSS was used to assess trait occupational stress. The JSS consists of 30 items that pertain to a wide range of occupations. The JSS features two primary factors of work stress: job pressure and lack of organizational support. Previous research using the JSS has found its various subscales and composite scales demonstrate high reliability ( $\alpha=.70$ to .93 ; Fiksenbaum, 1999; Gellis, 2001; Spielberger \& Reheiser, 1994a, 1994b; Spielberger, Reheiser, Reheiser, \& Vagg, 2000). 
Demographic and Vehicle Information. Demographic information included age, gender, occupation, gross salary, number of years in current position, marital status, and number of children. Vehicle information included driving experience, average daily driving time, type of vehicle driven, type of transmission, and age of current vehicle.

\section{Procedure}

As a replication and extension of previous research, the procedures followed in the current study were virtually identical to those in past studies (Hennessy \& Wiesenthal, 1997; Hennessy et al., 2000). During an initial discussion, informed consent was obtained and instructions regarding the experimental procedure were given. Following the instruction period, participants completed the demographic and vehicle information package, the JSS, and the DBIGen. Participants then provided information regarding their regular travel route along one or more of Toronto's major arterial highways. All measures were administered only during the participants' usual afternoon commute from work to home. The most common route among commuters was Highway 401, the major east-west traffic artery for Toronto. The average daily traffic on this highway for the Toronto area in 2003 was estimated to be over 400,000 vehicles, making it one of the busiest highways in the world (L. Tasca of the Ontario Ministry of Transportation, personal communication, February 19, 2003). For each participant, two areas along his or her regular commuting route were chosen: one that was typically low in traffic congestion and one that was typically high in traffic congestion. A landmark unique to each area was then selected, so that it could subsequently be used during the participant's journey as a cue to pull off the highway, park the vehicle, and initiate a cellular telephone call to the experimenter. An exit at least half way through the high and low congestion areas was chosen to ensure that the participant experienced the high or low congestion condition before leaving the 
highway. An appropriate parking place was also selected in advance to prevent any concern about parking from contributing to state driver stress. Both the low and high congestion telephone interviews were scheduled during a single journey.

Drivers were divided into those who typically encountered high prior to low traffic volumes in the course of their afternoon/evening commute from work to home and those who encountered low prior to high volumes. This counterbalancing eliminated possible confounding effects of fatigue or practice on state driver stress. Upon reaching their first designated landmark (i.e., for the low or high congestion area), participants searched for their previously selected exit and proceeded to the parking area chosen as the site of the cellular telephone call to the experimenter. During this call, the SDSQ was administered verbally. Upon completion of the first telephone interview, the cellular telephone call was terminated and participants returned to the highway and continued the commute until the second landmark was reached. The same procedure was followed for the second congestion condition, after which participants proceeded home.

Results

State Driver Stress as a Function of Demographic Characteristics

Consistent with previous findings ${ }^{1}$ (Gulian, Glendon, Matthews, Davies, \& Debney, 1990; Krahé \& Fenske, 2002; Renge, 2000), Pearson product-moment correlations indicated that the age of participants and their amount of driving experience were negatively associated with state driver stress in high traffic congestion $(r=-.33, p<.05$; and $r=-.36, p<.05$, respectively). Older participants, who are also more experienced drivers $(r=.98)$, reported less stress when encountering heavier traffic volumes. No other significant effects were found. 


\section{Effects of Traffic Congestion and Driver Gender}

In order to examine the influences of congestion level and driver gender on state driver stress, a split-plot factorial analysis was performed with the two levels of congestion as the within-groups variable and driver gender as the between-groups variable. Pearson productmoment correlations were conducted among state stress scores, time urgency scores, and perceived control scores reported in each of the traffic congestion levels. Positive relationships were found between the reported state stress scores and the time urgency scores in both the low and high congestion conditions $(r=.41, p<.01 ; r=.57, p<.01)$. Likewise, negative relationships were found between reported state stress scores and perceived control scores in both low and high congestion conditions $(r=-.33, p<.05 ; r=-.32, p<.05)$. Given these relationships, the influence of time urgency and perceived control on state driver stress were removed from the factorial analysis by treating these variables as covariants.

In support of the first hypothesis, state driver stress was significantly greater in the high than it was in the low congestion condition, $F(1,36)=7.03, p<.05$, partial $\eta^{2}=.16$. Consistent with previous research (Hennessy \& Wiesenthal, 1999), neither driver gender, $F(1,36)=0.30, p$ $>.05$, nor the interaction between congestion level and driver gender, $F(1,36)=1.04, p>.05$, were significant. No statistically significant order effects regarding exposure to traffic congestion were found.

Given that only minor differences in the ratings of congestion in the high and low congestion conditions were obtained in the first quarter of the sample, an item asking participants to estimate their average speed in the previous period of travel was added to the end of the SDSQ. Of the 30 participants who were asked about their average speed, the mean response for the low congestion condition was $103.89 \mathrm{~km} / \mathrm{h}(S D=16.63)$ and for the high congestion 
condition, it was $63.83 \mathrm{~km} / \mathrm{h}(S D=32.19)$. An $F_{\text {ratio }}$ test of the variances in these speed estimates revealed that variance in reported speed in the high congestion condition was significantly greater than it was in the low congestion condition, $F_{\text {ratio }}(29,29)=3.75, p<.01$.

Scores on the SDSQ in both high and low traffic congestion were also compared with scores found in previous studies (i.e., Hennessy \& Wiesenthal, 1999, Hennessy et al., 2000) that used the current study's methodology. Participants' state stress scores were comparable to those of previous studies under conditions of low traffic congestion. In high traffic congestion, the current sample displayed lower state stress than did previous samples, $F(2,157)=7.10, p<.001$. Using a Tukey/Kramer test to accommodate for minor differences in group size, the multiplecomparisons analysis determined that the current sample reported significantly lower scores than the sample examined by Hennessy and Wiesenthal $(1999), Q(2,157)=5.17, p<.001$. Interestingly, the SDSQ scores from this latter study were also significantly greater than those reported by Hennessy et al. (2000), $Q(2,157)=3.47, p<.05$.

\section{Predictors of State Driver Stress}

In order to assess predictors of state driver stress in both high and low traffic congestion, separate multiple regressions were computed for each condition. A series of $t$ tests comparing male and female participants on each of the main effect predictor variables revealed no significant differences. Time urgency and perceived control were included in the regression analysis primarily as control variables. Preliminary paired-sample $t$ tests comparing time urgency and perceived control in high versus low traffic congestion were conducted. Only perceived control was found to differ between the two levels of traffic congestion, $t(41)=3.37, p<.01$, such that perceived control was greater in the low traffic congestion condition. In addition, an $F_{\text {ratio }}$ test of the variances in perceived control in low $(S D=15.91)$ versus high $(S D=26.02)$ 
traffic congestion revealed a significant difference, such that perceived control scores were more varied for drivers in the high congestion condition than they were in the low congestion condition, $F_{\text {ratio }}(41,41)=2.68, p<.01$. The main effect predictors tested in the regression analysis included gender, trait driver stress, and occupational stress. Overall composite JSS scores were chosen to represent the occupational stress construct, given that only one JSS scale could be entered into the regression. Use of multiple JSS subscales would have caused problems of singularity and multicollinearity, and it would have weakened the analysis. The overall composite JSS scale was chosen because, like some of the other subscales, it demonstrated a requisite correlation with SDSQ scores and because it possessed theoretical superiority over the other JSS subscales ${ }^{2}$. Furthermore, the three-way interaction among the three main predictors and all two-way interactions were included in each initial model. In order to reduce problems of multicollinearity, all interactions were centered (Aiken \& West, 1991; Tabachnick \& Fidell, 2001). In addition, centered main effects were used in all regression runs. Kline and Dunn (2000) have found identical results when entering centered and noncentered main effects into regression analyses.

A hierarchical entry stepwise procedure was used to produce final models that would include only two classes of effects: those that were statistically significant and those that, significant or not in themselves, were implicated in a significant interaction. The procedure was to enter all main effects and two-way interactions forcibly and to add the three-way interaction stepwise on the first run. If the three-way interaction was significant, all significant and implicated variables would be retained. Otherwise, the second run would involve entering all main effects forcibly and all two-way interactions stepwise. This pattern would be followed until, if necessary, all main effects would be entered stepwise on the final run. This statistical 
strategy has been reported in greater detail elsewhere (e.g., Kohn, Gurevich, Pickering, \& Macdonald, 1994; Kohn \& Macdonald, 1992), and was chosen because of its greater statistical power in deleting non-contributory predictors. To confirm that any significant relationships found by the regression analyses were consistent for the entire distribution of scores, scatterplots of each of the continuous predictor variables and the dependent variables were examined.

Low congestion. The final regression model for low traffic congestion appears in Table 1. As predicted, time urgency and trait driver stress, along with job stress, made significant positive contributions to state driver stress in low traffic congestion. Perceived control approached significance as a negative predictor $(p=.10)$; however, it was retained in the model because its $p$ value for $F$ fell directly between the minimum level of .05 for inclusion in the model and the maximum level of .10 for exclusion from the model. In addition, perceived control accounted for a large percentage $(10 \%)$ of the variance in state driver stress. Collectively, the predictors in the final model for low traffic congestion accounted for approximately $57 \%$ of the variance in state driver stress. Interestingly, although excluded on the second round of the regression analysis, the interaction of trait driver stress and job stress predicted state driver stress at a $p$ value of .14. This interaction suggests that in low traffic congestion, where the driving environment has minimal impact on cognitive resources, high trait stress drivers will allow their occupational stress to magnify their experience of state driver stress. Although this finding is inconclusive in the current study, it merits investigation in future research.

Insert Tables 1 and 2 here 
High congestion. The final regression model for high traffic congestion appears in Table 2. As hypothesized, state driver stress was greater among highly time urgent drivers and high trait stress drivers. Perceived control also negatively contributed to state driver stress. Together, these predictors accounted for $57 \%$ of the variability in state driver stress in high traffic congestion. Unlike the regression model for low traffic congestion, and contrary to predictions, neither job stress nor the interaction between job and trait driver stress came close to predicting state driver stress.

\section{Discussion}

Time Urgency as a Predictor of State Driver Stress

The current research found that participants reported greater state driver stress under conditions of high traffic congestion than they did under conditions of low traffic congestion. This finding is consistent with other empirical research (Lajunen, Parker, \& Summala, 1999; Shinar, 1998) that cites congested roadways as a contributing factor to improper driving behavior. Beyond the level of traffic congestion, the current research also found that time urgency was a significant predictor of state driver stress under conditions of both high and low traffic congestion. When drivers were more hurried, they were more likely to report driver stress than when they had a more flexible time schedule. When faced with time constraints, other vehicles are perceived as impediments to reaching a destination on time. Delays and obstacles can cause increased frustration, anxiety, and negative affect (Hennessy et al., 2000). In terms of the transactional model of driver stress (Gulian et al., 1989; Matthews, 2001; Matthews et al., 1991), time urgency can negatively influence the cognitive appraisal of a stressful situation, thereby producing increased tension and possibly more aggressive driving behavior. 


\section{Perceived Control as a Predictor of State Driver Stress}

Perceived control over the driving situation plays an integral role in determining the physiological, psychological, and behavioral strain experienced in the driving environment (Koslowsky, 1997). In the current study, perceived control was a significant predictor of state driver stress under high congestion conditions, and it approached significance under low congestion conditions. Interpretation of the low congestion findings is not as clear. Although it is possible that the study's small sample size limited the statistical power of the regression analysis, it is also possible that perceived control plays less of a role in situations with few environmental stressors. According to Lazarus and Folkman's (1984) cognitive stress model, belief in one's control over a situation is a primary psychological coping resource that combats the tendency to experience a negative situation as stressful. When the highway is not posing stressful challenges, there is no diminution of perceived controllability, with drivers maintaining maximal perceptions of control. A comparison of the variance in perceived control in low versus high traffic congestion supports this interpretation. When faced with more crowded traffic conditions, the perception of control varied greatly for drivers and significantly influenced the degree to which they found the driving environment stressful. When encountering minimal traffic congestion, the perception of control was greater and less varied for drivers, suggesting that the driving environment was not posing a threat to this psychological coping resource.

\section{Trait Driver Stress as a Predictor of State Driver Stress}

Previous research has found that self-reported trait driver stress influences self-reported state driver stress. Yagil (2001) demonstrated that when asked to read and react to written scenarios describing frustrating driving situations, high trait anxiety drivers exhibited greater irritability than did low trait anxiety drivers. Using the same methodology as the current study, 
previous research in the actual driving environment has found that compared with low trait stress drivers, high trait stress drivers reported significantly more state driver stress when commuting (Hennessy \& Wiesenthal, 1997, 1999; Hennessy et al., 2000). Furthermore, when contrasting aggressive and nonaggressive drivers, the former have scored higher on both self-report (Galovski \& Blanchard, 2002) and physiological measures of stress (Malta et al., 2001). Consistent with these findings and with the transactional model of driver stress (Gulian et al., 1989; Matthews, 2001; Matthews et al., 1991), the current research indicated that trait driver stress was a significant predictor of state driver stress levels in both high and low traffic congestion. Drivers who demonstrated greater trait driver stress also experienced a greater degree of stress in the roadway environment.

\section{Occupational Stress as a Predictor of State Driver Stress}

Based on previous research concerning the role of daily hassles in the roadway environment (Hennessy et al., 2000), the current study hypothesized that under conditions of high traffic congestion, state driver stress would be predicted by the interaction of occupational stress and trait driver stress susceptibility. Specifically, state driver stress would be greater among high trait stress drivers, but it would be exaggerated among those with heightened job stress. However, the current study failed to demonstrate these expectations. Instead, occupational stress was found to be a significant predictor of state driver stress in low traffic congestion, but not high traffic congestion. Furthermore, an interaction between job stress and trait driver stress was not a significant predictor of state driver stress under either condition of traffic congestion, although the interaction did approach significance in the low congestion condition. It is possible that the nonsignificant interaction in the low congestion condition is a true effect but, with data for only 42 participants, statistical power was limited. It is possible that a larger sample size 
would identify the interaction between job and trait driver stress as a statistically significant predictor of state driver stress under conditions of low traffic congestion.

Although the manipulation check included in the current study ensured that participants experienced one set of traffic conditions that were more congested than another, there was no certainty that the levels of congestion included within each participant's high and low congestion conditions were homogeneous. That is, one driver may have encountered crowded, but still moving, traffic in the high congestion condition, whereas another may have encountered completely stopped traffic. Furthermore, it is possible that the level of traffic encountered by one participant in the low congestion condition may have been equivalent to the level of traffic encountered by another participant in the high congestion condition. Although the perception of high traffic congestion may relate to a variety of individual difference variables, the fact that participants encountered heavier traffic as opposed to heavy traffic in their high congestion condition may have had a significant impact on the role of occupational stress in predicting drivers' reactions.

Several items provide support for the contention that participants in the current sample did not actually encounter extremely heavy traffic congestion in their high congestion condition. The mean estimated speed for the low congestion condition was $103.98 \mathrm{~km} / \mathrm{h}$, and for the high congestion condition was $63.83 \mathrm{~km} / \mathrm{h}$. These figures suggest that although participants encountered more vehicles on the highway in their high congestion condition, they did not encounter extreme traffic congestion. Furthermore, the variance in speed in the high congestion condition was significantly greater than the variance in the low congestion condition. Interestingly, four participants reported greater speed in their high congestion condition than they did in their low congestion condition. 
Further evidence that severe congestion was not encountered by the current sample was found by comparing their SDSQ scores with those of previous samples. Although scores were comparable in low congestion, the current SDSQ scores in high congestion were lower than those of Hennessy and Wiesenthal's (1999) sample. Given that participants reported significantly less driver stress in the high congestion condition, it is possible that this is the result of encountering less extreme congestion conditions. Moreover, the previous research was conducted at a time when major construction was occurring along Highway 401 that intensified congestion and lengthened delays (D. A. Hennessy, personal communication, August 21, 2003). Since that time, an additional parallel highway has opened, alleviating the volume of traffic on Highway 401.

One of the conceptual possibilities is that the occurrence of job stress by trait driver stress interaction effects on state driver stress is curvilinearly related to traffic congestion classified into three levels: low, crowded but moving, and stop and go. In terms of the findings of the current study, it is possible that low traffic volume requires minimal cognitive resources, which in turn allow occupational stressors to have an impact on a driver's perception of the roadway. When the traffic volume is higher, but not congested enough to significantly slow traffic, as was likely the case in the current study, the driver may require more attention to navigate safely through the crowded roadway. This higher cognitive demand may prevent occupational stressors from entering a driver's immediate consciousness and adding to the immediate experience of driver stress. Based on this conceptual interpretation of the current findings, and consistent with the findings of Hennessy et al. (2000), it would follow that severe traffic congestion (i.e., where a driver is completely stopped or merely inching forward) would again require the use of only 
minimal cognitive resources, thereby leaving ample opportunity for a driver to consider the day's workplace events and to allow them to influence his or her current mood and stress levels.

\section{Limitations of and Future Directions for the Current Study}

The current study highlighted the importance of adding a condition of intermediate traffic congestion in future research rather than relying upon only high and low traffic congestion conditions. An intermediate level of traffic, where drivers perceive significant vehicular crowding without slowing of speed, may be an important situation to consider when theorizing about the interaction of person- and situation-related variables in the driving environment. The hypothesis that the occurrence of job stress by trait driver stress interaction effects on state driver stress is curvilinearly related to three levels of traffic congestion merits further investigation.

Future research should also examine both the possible carryover of stress from the driving environment to the home or workplace and the rate of dissipation of such carryover effects. Preliminary studies examining the impact of commuter stress on postcommute behavior have found that commuting reduces frustration tolerance (White \& Rotton, 1998) and increases social hostility and the perception of workplace hassles (Hennessy, 2003). Other recent findings on driver stress (Van Rooy, 2003; White \& Rotton, 1998) support the older research on frustration and anger as being short-lived (Doob \& Climie, 1972; Konecni, 1975). 


\section{References}

Aiken, L. S., \& West, S. G. (1991). Multiple regression: Testing and interpreting interactions. Newbury Park, CA: Sage Publications Inc.

Cooper, C. L., \& Payne, R. (Eds.). (1988). Causes, coping and consequences of stress at work. Toronto: John Wiley \& Sons.

Doob, A. N., \& Climie, R. J. (1972). Delay of measurement and the effects of film violence. Journal of Experimental Social Psychology, 8, 136-143.

Fiksenbaum, L. (1999). Social support and coping as moderators of work-related stress and burnout. Unpublished master's thesis, York University, North York, Ontario, Canada.

Galovski, T., \& Blanchard, E. B. (2002). Psychological characteristics of aggressive drivers with and without intermittent explosive disorder. Behaviour Research and Therapy, 40, 11571168.

Gellis, Z. D. (2001). Job stress among academic health center and community hospital social workers. Administration in Social Work, 25, 17-33.

Glendon, A. I., Dorn, L., Matthews, G., Gulian, E., Davies, D.R., \& Debney, L. M. (1993). Reliability of the Driving Behaviour Inventory. Ergonomics, 36, 719-726.

Gulian, E., Glendon, A. I., Matthews, G., Davies, D. R., \& Debney, L. M. (1990). The stress of driving: A diary study. Work \& Stress, 4, 7-16.

Gulian, E., Matthews, G., Glendon, A. I., Davies, D. R., \& Debney, L. M. (1989). Dimensions of driver stress. Ergonomics, 32, 585-602.

Hennessy, D. A. (2003, August). From driver stress to workplace aggression. Paper presented at the $111^{\text {th }}$ convention of the American Psychological Association, Toronto, Canada. 
Hennessy, D. A., \& Wiesenthal, D. L. (1997). The relationship between traffic congestion, driver stress and direct versus indirect coping behaviours. Ergonomics, 40, 348-361.

Hennessy, D. A., \& Wiesenthal, D. L. (1999). Traffic congestion, driver stress, and driver aggression. Aggressive Behavior, 25, 409-423.

Hennessy, D. A., Wiesenthal, D. L., \& Kohn, P.M. (2000). The influence of traffic congestion, daily hassles, and trait stress susceptibility on state driver stress: An interactive perspective. Journal of Applied Biobehavioral Research, 5, 162-179.

Kline, T. J. B., \& Dunn, B. (2000). Analysis of interaction terms in structural equation models: A non-technical demonstration using the deviation score approach. Canadian Journal of Behavioural Science, 32, 127-132.

Kohn, P. M., Gurevich, M., Pickering, D. I., \& Macdonald, J. E. (1994). Alexithymia, reactivity, and the adverse impact of hassles based stress. Personality and Individual Differences, $16,805-812$.

Kohn, P. M., Hay, B. D., \& Legere, J. J. (1994). Hassles, coping styles, and negative well-being. Personality and Individual Differences, 17, 169-179.

Kohn, P. M., \& Macdonald, J. E. (1992). Hassles, anxiety, and negative well-being. Anxiety, Stress, and Coping, 5, 151-163.

Konecni, V. J. (1975). The mediation of aggressive behavior: Arousal level versus anger and cognitive labelling. Journal of Personality and Social Psychology, 32, 706-712.

Koslowsky, M. (1997). Commuting stress: Problems of definitions and variable identification. Applied Psychology: An International Review, 46, 153-173.

Krahé, B., \& Fenske, I. (2002). Predicting aggressive driving behavior: The role of macho personality, age, and power of car. Aggressive Behavior, 28, 21-29. 
Lajunen, T., Parker, D., \& Summala, H. (1999). Does traffic congestion increase driver aggression? Transportation Research Part F, 2, 225-236.

Lazarus, R. S., \& Folkman, S. (1984). Stress, appraisal, and coping. New York: Springer.

Lindquist, E. F. (1953). Design and analysis of experiments in psychology and education. Boston: Houghton Mifflin Company.

Mackay, C. J., Cox, T., Burrows, C. G., \& Lazzerini, A. J. (1978). An inventory for the measurement of self reported stress and arousal. British Journal of Social and Clinical Psychology, 17, 283-284.

Malta, L. S., Blanchard, E. B., Freidenberg, B. M., Galovski, T. E., Karl, A., \& Holzapfel, S. R. (2001). Psychophysiological reactivity of aggressive drivers: An exploratory study. Applied Psychophysiology and Biofeedback, 26, 95-116.

Matthews, G. (2001). A transactional model of driver stress, In P. A. Hancock \& P. A. Desmond (Eds.), Stress, workload, and fatigue (pp. 133-163). Mahwah, NJ: Lawrence Erlbaum Associates Publishers.

Matthews, G., Dorn, L., \& Glendon, A. I. (1991). Personality correlates of driver stress. Personality and Individual Differences, 12, 535-549.

Renge, K. (2000). Effect of driving experience on drivers' decoding process of roadway interpersonal communication. Ergonomics, 43, 27-39.

Shinar, D. (1998). Aggressive driving: The contribution of the drivers and the situation. Transportation Research Part F, 1, 137-160.

Spielberger, C. D., \& Reheiser, E. C. (1994a). Job stress in university, corporate, and military personnel. International Journal of Stress Management, 1, 19-31. 
Spielberger, C. D., \& Reheiser, E. C. (1994b). The Job Stress Survey: Measuring gender differences in occupational stress. Journal of Social Behavior and Personality, 9, 199218.

Spielberger, C. D., Reheiser, E. C., Reheiser, J. E., \& Vagg, P. R. (2000). Measuring stress in the workplace: The Job Stress Survey, In D. T. Kenny, J. C. Carlson, E. J. McGuigan, \& J. L. Sheppard (Eds.), Stress and health: Research and clinical applications (pp. 397-409). Amsterdam, The Netherlands: Harwood Academic Publishers.

Spielberger, C. D., \& Vagg, P. R. (1999). Professional manual for the Job Stress Survey (JSS). Odessa, FL: Psychological Assessment Resources, Inc. (PAR).

Tabachnick, B. G., \& Fidell, L. S. (2001). Using multivariate statistics (4 ${ }^{\text {th }}$ ed.). Toronto: Allyn and Bacon.

Van Rooy, D. L. (2003). Effects of commute characteristics and cell phone use on affect and candidate evaluations: A field experiment. Unpublished master's thesis, Florida International University, Miami, FL.

White, S. M., \& Rotton, J. (1998). Type of commute, behavioral aftereffects, and cardiovascular activity: A field experiment. Environment and Behavior, 30, 763-781.

Wiesenthal, D. L., Hennessy, D. A., \& Totten, B. (2000). The influence of music on driver stress. Journal of Applied Social Psychology, 30, 1709-1719.

Yagil, D. (2001). Interpersonal antecedents of drivers' aggression. Transportation Research Part $F, 4,119-131$. 


\section{Author Notes}

This manuscript is based on research conducted by Christine M. Wickens in partial fulfillment of the M.A. degree requirements of York University. The research was supervised by Professor David L. Wiesenthal. The authors wish to thank Professors Esther R. Greenglass and Paul M. Kohn who served on Christine M. Wickens' thesis committee. Further valuable assistance was provided by Lisa Fiksenbaum, Mirka Ondrack, Faruk Gafic, Jonathan Belman, Nicole Azzi, and Kathy Mazurek. The authors also wish to thank the anonymous reviewers for their helpful comments, and Professor Charles D. Spielberger who kindly provided the Job Stress Survey for use in the current study.

Correspondence concerning this article should be addressed to Professor David L. Wiesenthal, 288 Behavioural Sciences Building, York University, 4700 Keele Street, Toronto, Ontario, M3J 1P3, Canada.E-mail: davidw@yorku.ca 


\section{Footnotes}

${ }^{1}$ Because a very conservative power analysis was used, the sample size in the current study was slightly below preferred levels. If a less stringent effect-size estimate been used, as suggested by the previous findings of Hennessy et al. (2000), the sample size in the current study would have met an acceptable criterion for a power test.

${ }^{2}$ Scores on the JSS were compared to available normative data for both managerial/professional and clerical/skilled-maintenance job types (Spielberger \& Vagg, 1999). Females in the current sample appeared to present a more homogeneous set of JSS scores than did female participants of either job type in the normative sample. $F_{\text {ratio }}$ tests comparing the variance of the current female sample's JSS scores with that of the normative female sample's scores failed to attain significance. Males in the current sample reported significantly higher JSS scores than their normative male counterparts, $F(2,856)=10.02, p<.001$. Specifically, they reported higher JSS scores than did the clerical and skilled-maintenance workers, as indicated by a multiple-comparisons one-sample $t$ test, $t(28)=3.67, p<.05$. The comparison of JSS scores for male participants in the current study and in the normative samples used aggregated data. For this reason, a standard Levene test for equality of variances could not be conducted. An $F_{\text {ratio }}$ test of the two normative samples, which produced the highest and lowest variances of the three groups, was difficult to interpret because of the extremely large sample sizes which maximized statistical power. Nonetheless, the analysis of variance is a remarkably robust test (Lindquist, 1953). The one-sample $t$ test was used for multiple-comparisons analysis because of the vastly different group sizes involved in the analysis. An identical comparison of the managerial/professional workers and the current sample indicated no significant difference. Furthermore, the mean total score for the current sample falls within the $70^{\text {th }}$ percentile, as 
identified in the JSS manual (Spielberger \& Vagg, 1999). Although an analysis of variance revealed a significant difference among the mean job stress scores of the three overall samples, $F(2,1773)=4.02, p<.05$, pairwise comparisons did not. 


\section{Table 1}

Predictors of State Driver Stress in Low Traffic Congestion

\begin{tabular}{|c|c|c|c|c|}
\hline Criterion & Predictor & $b$ & $T$ & $\begin{array}{c}R^{2} \\
\text { Change }\end{array}$ \\
\hline \multirow{6}{*}{$\begin{array}{l}\text { State Driver Stress: } \\
\text { Low Congestion }\end{array}$} & Trait Driver Stress & .489 & $3.617 * * *$ & .363 \\
\hline & Perceived Control & -.242 & -1.925 & .096 \\
\hline & Time Urgency & .275 & $2.745^{* *}$ & .053 \\
\hline & Job Stress & .266 & $2.173^{*}$ & .055 \\
\hline & Intercept & 40.136 & 3.247 & \\
\hline & \multicolumn{4}{|c|}{$R^{2}=.57, F(4,37)=12.13, p<.001$} \\
\hline $\begin{array}{l}N=42 \\
* p<.05 \\
* * p<.01 \\
* * * p<.001\end{array}$ & & & & \\
\hline
\end{tabular}


Table 2

Predictors of State Driver Stress in High Traffic Congestion

\begin{tabular}{|c|c|c|c|c|}
\hline Criterion & Predictor & $b$ & $T$ & $\begin{array}{c}R^{2} \\
\text { Change }\end{array}$ \\
\hline \multirow{5}{*}{$\begin{array}{l}\text { State Driver Stress: } \\
\text { High Congestion }\end{array}$} & Time Urgency & .385 & $4.301 * * *$ & .326 \\
\hline & Trait Driver Stress & .505 & $3.473 * * *$ & .191 \\
\hline & Perceived Control & -.193 & $-2.239 *$ & .056 \\
\hline & Intercept & 34.868 & 4.875 & \\
\hline & \multicolumn{4}{|c|}{$R^{2}=.57, F(3,38)=17.00, p<.001$} \\
\hline $\begin{array}{l}N=42 \\
* p<.05 \\
* * * p<.001\end{array}$ & & & & \\
\hline
\end{tabular}

